\title{
THE TENSILE BEHAVIOR OF $\mathrm{Ti}_{36} \mathrm{Ni}_{49} \mathrm{Hf}_{15} \mathrm{HIGH}$ TEMPERATURE SHAPE MEMORY ALLOY
}

\author{
Y.Q. Wang, Y.F. Zheng, W. Cai and L.C. Zhao \\ School of Materials Science and Engineering, Harbin Institute of Technology, Harbin 150001, \\ Peoples Republic of China \\ (Received January 5, 1999) \\ (Accepted in revised form March 5, 1999)
}

\section{$\underline{\text { Introduction }}$}

Recently, ternary Ti-Ni-Hf alloys have attracted great interest in the field of high temperature shape memory materials research and development. Extensive studies have been made on its manufacture process [1], constitutional phases [2], phase transformation behavior [2-3], the structure [4-5], substructure [5-6] and interface structure [7] of martensite and the precipitation behavior during ageing [8].Yet up to date there is no report about the fundamental mechanical properties of Ti-Ni-Hf alloys, such as the stress-strain data, the variation laws of the yield strength and elongation with the temperature. In the present study, tensile tests at various temperatures are employed to investigate the mechanical behavior of Ti-Ni-Hf alloy with different matrix structures, from full martensite to full parent phase structure, with the corresponding deformation mechanism discussed.

\section{Experimental}

A $\mathrm{Ti}_{36} \mathrm{Ni}_{49} \mathrm{Hf}_{15}$ alloy was prepared by consumable arc melting under an $\mathrm{Ar}$ atmosphere in a watercooled copper crucible of $60 \mathrm{~mm}$ in diameter. The electrode was a compact of $99.92 \mathrm{wt} . \%$ sponge Ti, 99.95 wt.\% electrolytic Ni plate and $99.90 \mathrm{wt} \%$ Hf shot. Then the ingot was remelted twice to ensure composition homogeneity by a levitation method under an Ar atmosphere and the melt was poured into a graphite mold of $35 \mathrm{~mm}$ in diameter. After homogenizing at $1223 \mathrm{~K}$ for 1.5 hours, the ingot was hot rolled into plate of $2.1 \mathrm{~mm}$ thickness. $0.5 \times 2 \times 50 \mathrm{~mm}^{3}$ specimens were cut in the rolling direction, mechanically polished and solution-treated at $1173 \mathrm{~K}$ for 1 hour. The phase transformation temperatures under this condition were determined by differential scanning calorimeter to be $\mathrm{M}_{\mathrm{f}}=421 \mathrm{~K}, \mathrm{M}_{\mathrm{s}}=$ $452 \mathrm{~K}, \mathrm{~A}_{\mathrm{s}}=489 \mathrm{~K}, \mathrm{~A}_{\mathrm{f}}=504 \mathrm{~K}$. Tensile test was conducted in air with an Instron-1186 Model machine at a strain rate of $1.7 \times 10^{-4} \cdot \mathrm{S}^{-1}$. The accuracy of the test temperature was controlled within $\pm 0.5 \mathrm{~K}$. The specimen was heated from room temperature to the test temperature and kept for 2 minutes before tensile stress was applied. After high temperature testing, no obvious oxidation was detected on the specimen surface. In order to examine shape memory effect, two parallel scratches with a distance of $\mathrm{L}_{0}$ were drawn near the ends of the gauge portion before tensile testing. $\mathrm{L}$ and $\mathrm{L}_{\mathrm{T}}$ represent the length after loading followed by unloading and that after heating well above the Af temperature, respectively. The real tensile strains could be measured directly with the aid of an optical microscope at room 


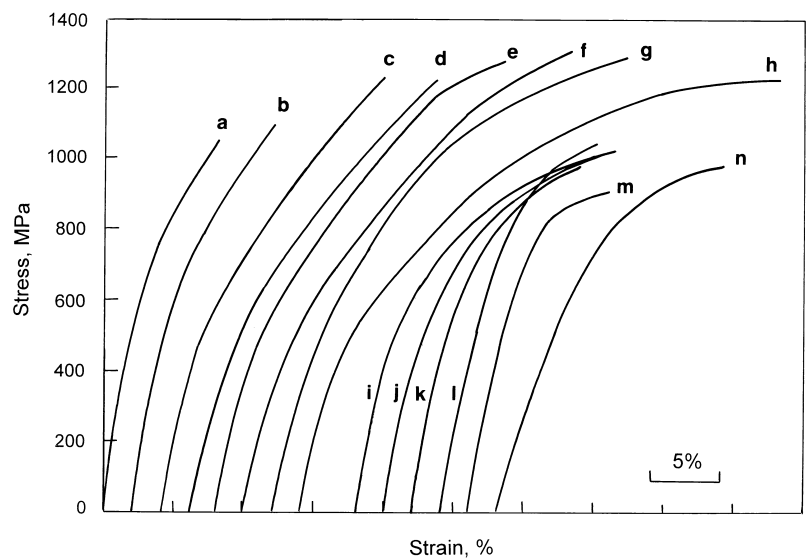

Figure 1. Stress-strain curves at different temperatures for the $\mathrm{Ti}_{36} \mathrm{Ni}_{49} \mathrm{Hf}_{15}$ alloy, (a). 293K; (b). 323K; (c). 373K; (d). 423K; (e). $448 \mathrm{~K}$; (f). $473 \mathrm{~K}$; (g). 493K; (h). $513 \mathrm{~K}$; (i). $533 \mathrm{~K}$; (j). 553K; (k). 573K; (l). 593K; (m). 623K; (n). $673 \mathrm{~K}$.

temperature and calculated as $\epsilon_{\mathrm{P}}=\left(\mathrm{L}-\mathrm{L}_{0}\right) / \mathrm{L}_{0} \times 100 \%$, and the shape recovery ratio as $\mathrm{R}=(\mathrm{L}-$ $\left.\mathrm{L}_{\mathrm{T}}\right) /\left(\mathrm{L}-\mathrm{L}_{0}\right) \times 100 \%$. The fracture surface observation was conducted on an S-570 Model SEM.

\section{$\underline{\text { Results and Discussion }}$}

\section{Stress-strain curves}

Fig. 1 shows a series of stress-strain ( $\mathrm{S}-\mathrm{S}$ ) curves obtained at different temperatures for the $\mathrm{Ti}_{36} \mathrm{Ni}_{49} \mathrm{Hf}_{15}$ alloy, in which (a)-(f), (h)-(n) and (g) correspond originally to the full martensite, the full parent phase and two phases coexisted matrix structures. The feature of the present S-S curves is similar to that of Ti-Ni-Pd [9] and cold-worked TiNi [10] shape memory alloys, but quite different from that of annealed TiNi shape memory alloys [11]. As well-known [12], when TiNi alloys, solution-treated or annealed after cold-working, are deformed in a martensitic state, the reorientation of martensite variants and/or detwinning occurs and the corresponding S-S curve exhibits a well defined yielding, a stress plateau with little work hardening and a Lüder's strain of about $8 \%$ before rapid work hardening; similar stress-strain behavior could also be observed when they are deformed in a parent phase state, with the deformation mechanism being the stress induced martensitic transformation. In contrast, for the present experimental alloy, the stress plateau completely disappears and high work hardening is constantly observed instead, irrespective of the tensile temperature. The high work hardening tends to result prematurely in dislocation slip during the reorientation of martensite variants or stress induced martensitic transformation.

\section{$\underline{\text { 2. Temperature dependence of the critical stress } \sigma_{0.2}}$}

Fig. 2 illustrates the variation of the $0.2 \%$ offset stress $\left(\sigma_{0.2}\right)$ with tensile temperature. Clearly, the yield stress versus temperature curve exhibits approximately S-shaped general feature observed in shape memory alloys. The negative temperature dependence of the critical stress is associated with the reorientation of martensite variant and/or detwinning in the low temperature range (below about 510K in Fig. 2) and dislocation slip in the high temperature range (above about 590K in Fig. 2), respectively. While the positive temperature dependence of the $\sigma_{0.2}$ stress between $510 \sim 590 \mathrm{~K}$ is attributed to the 


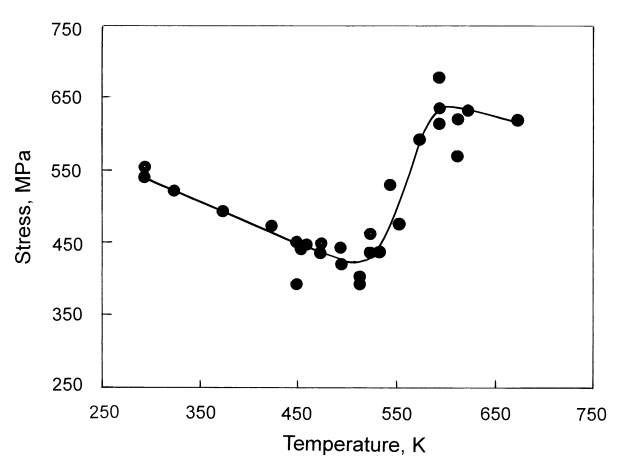

Figure 2. Temperature dependence of the critical stress $\sigma_{0.2}$ for the $\mathrm{Ti}_{36} \mathrm{Ni}_{49} \mathrm{Hf}_{15}$ alloy.

stress-induced martensitic transformation. The linear variation in the stress to induce martensite as a function of temperature above Ms satisfies the Clausius-Clapeyron equation. The $\mathrm{d} \sigma / \mathrm{dT}$ of the present alloy is determined to be about $3 \mathrm{MPa} / \mathrm{K}$, which is approximately equal to that (about $2.5 \mathrm{MPa} / \mathrm{K}$ ) for Ti-Pd-Cr alloy [13], but smaller than that $(5 \sim 20 \mathrm{MPa} / \mathrm{K})$ for TiNi alloys [14]. Compared with other shape memory alloys, the present experimental alloy shows a relatively high critical slip stress during the martensite variant reorientation. Our previous work showed that the substructure of martensite was (001) compound twin [6], whereas that in TiNi binary alloy was mainly $<011>$ Type II twin without the addition of Hf. The formation of (001) twin might involve in the slip of a/2 on (001) plane according to Kudoh et al. [15]. This indicates more irreversible defects might exist in the Ti-Ni-Hf (001) twinning martensite compared with TiNi $<011>$ Type II twinning martensite, which would inhibit the sequent reorientation process during tensile deformation and be disadvantageous to the shape memory effect.

\section{Temperature dependence of the elongation $\delta$}

Fig. 3 depicts the variation of the elongation $\delta$ with the tensile temperature for the $\mathrm{Ti}_{36} \mathrm{Ni}_{49} \mathrm{Hf}_{15}$ alloy. Clearly, the elongation $\delta$ is strongly dependent on the tensile temperature. Around room temperature, the elongation $\delta$ is about $10 \%$. With increasing tensile temperature, the elongation $\delta$ gradually increases and reaches a peak of about $30 \%$ at about $510 \mathrm{~K}$, slightly above Af temperature, and then decreases rapidly to a minimum at about 560K. Similar temperature dependence of the elongation $\delta$ has been observed in Ti-Ni-Nb alloys with wide hysteresis [16]. The maximum elongation at about $510 \mathrm{~K}$ is possibly attributed to the transformation-induced plasticity.

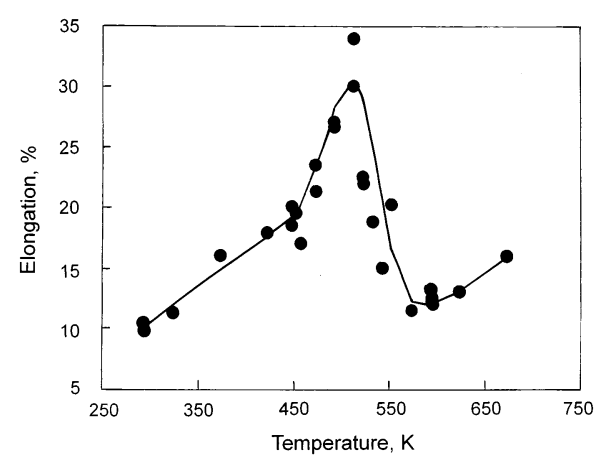

Figure 3. Temperature dependence of the elongation $\delta$ for the $\mathrm{Ti}_{36} \mathrm{Ni}_{49} \mathrm{Hf}_{15}$ alloy. 
TABLE 1

The shape recovery ratio $(\mathrm{R})$ for different strains $\varepsilon_{\mathrm{P}}$

\begin{tabular}{lcccccc}
\hline$\varepsilon_{\mathrm{P}}, \%$ & 2.01 & 2.93 & 3.51 & 4.03 & 4.97 & 6.01 \\
$\mathrm{R}, \%$ & 100 & 100 & 97.8 & 95.5 & 87.2 & 83.1 \\
\hline
\end{tabular}

\section{Strain recovery ratio}

The shape recovery ratio $\mathrm{R}$ for specimens deformed at $353 \mathrm{~K}$ to different tensile strains are listed in Table 1. It can be seen that the magnitude of the strain $\epsilon_{\mathrm{P}}$ greatly influences the shape recovery ratio $\mathrm{R}$. When the strain $\epsilon_{\mathrm{P}}$ is less than $2.93 \%$, a complete shape recovery was observed, i.e. $\mathrm{R}=100 \%$; when further increase of the strain $\epsilon_{\mathrm{P}}$, the shape recovery ratio gradually decreases. $\mathrm{R}=83.1 \%$ when $\epsilon_{\mathrm{P}}=$ $6.01 \%$. The above results indicate that about $3 \%$ completely recoverable strain can be obtained in the solution-treated $\mathrm{Ti}_{36} \mathrm{Ni}_{49} \mathrm{Hf}_{15}$ alloy. This value is obviously smaller than that for NiTi alloys but bigger that for NiAl [17] and Ti-Pd-X (X = Cr, Fe, Ni etc.) alloys $[9,13,18]$. The high critical stress for the reorientation of martensite variants and high work hardening are clearly to be responsible for the shape memory effect inferior to those of TiNi alloys.

\section{Existence or inexistence of superelasticity}

In order to test whether the experimental alloy exhibits superelasticity, the specimen was strained slightly above Af temperature. No superelasticity was observed when the specimen was elongated to some strain and then unloaded. However, when the elongated specimen was heated at $673 \mathrm{~K}$, an incomplete shape recovery was observed. These results implies that true plastic deformation occurred simultaneously during the stress-induced martensitic transformation and released the stored elastic strain energy, thereby increasing the stability of the stress-induced martensite and inhibiting the superelastic behavior. Similar results have also reported in TiNi [12], Ti-Ni-Nb [16] and Ti-Pd-Ni alloys $[9,18]$.

\section{Fracture surface of the tensile specimens}

Fig. 4 shows the SEM observation of fracture surface for the specimens with different original microstructures. The fracture surface is always normal to the tensile axis and no obvious necking is
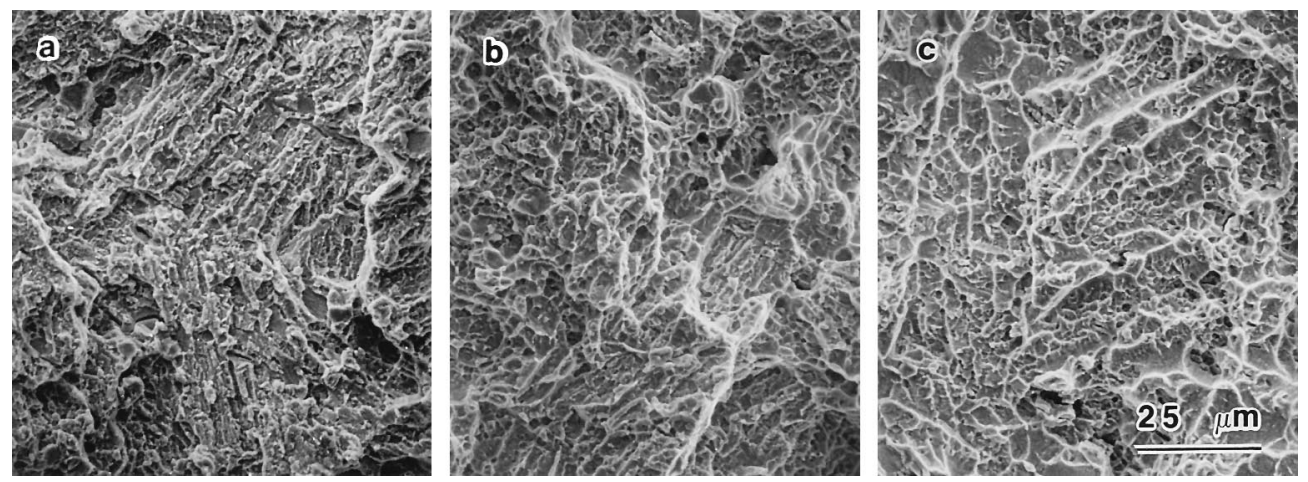

Figure 4. SEM observation of fracture surface for the $\mathrm{Ti}_{36} \mathrm{Ni}_{49} \mathrm{Hf}_{15}$ alloy specimens tensioned at (a) $293 \mathrm{~K}$; (b) $493 \mathrm{~K}$ and (c) $623 \mathrm{~K}$. 
observed. Fig. 4(b) shows a typical dimple fracture surface (the fracture strain is about 26\%). However a few cracks exist in Fig. 4(a) and (c), which exhibits partially brittle behavior (the fracture strain are $8 \%$ and $10 \%$, respectively).

\section{Conclusions}

The tensile behavior of the $\mathrm{Ti}_{36} \mathrm{Ni}_{49} \mathrm{Hf}_{15}$ alloy is characterized by continuous yielding and high work hardening in the temperature range from $293 \mathrm{~K}$ to $673 \mathrm{~K}$. The critical stress for martensite variant reorientation is relatively high and a maximum elongation of about $30 \%$ is observed at about $510 \mathrm{~K}$. About $3 \%$ completely recoverable tensile strain is obtained when the specimen is deformed at $353 \mathrm{~K}$. No superelasticity is observed. The high critical stress for the reorientation of martensite variants and high work hardening are clearly to be responsible for the shape memory effect inferior to those of TiNi alloys.

\section{$\underline{\text { Acknowledgment }}$}

Project 59471029 supported by the National Natural Science Foundation of China.

\section{References}

1. S. M. Tuominen, in Proceedings of the 1st International Conference on Shape Memory and Superelastic Technologies, ed. A. R. Pelton, D. Hodgson and T. Duerig, p. 49, International Organization on SMST (1994).

2. P. Olier, J. C. Brachet, J. L. Bechade, C. Foucher, and G. Guenin, J. Phys. IV. C8, 741 (1995).

3. D. R. Angst, P. E. Thoma, and M. Y. Kao, J. Phys. IV. C8, 747 (1995).

4. P. L. Potapov, A. V. Shelyakov, A. A. Gulyaev, E. L. Svistunova, N. M. Matveeva, and D. Hodgson, Mater. Lett. 32 , 247 (1997).

5. X. D. Han, W. H. Zou, R. Wang, Z. Zhang, and D. Z. Yang, Acta Mater. 44, 3711 (1996).

6. Y. F. Zheng, W. Cai, J. X. Zhang, Y. Q. Wang, L. C. Zhao, and H. Q. Ye, Mater. Lett. 36, 142 (1998).

7. Y. F. Zheng, L. C. Zhao, and H. Q. Ye, Scripta Mater. 38, 1249 (1998).

8. X. D. Han, R. Wang, Z. Zhang, and D. Z. Yang, Acta Mater. 46, 273 (1998).

9. D. Golberg, Y. Xu, Y. Murakami, S. Morito, and K. Otsuka, Scripta Metall. Mater. 30, 1349 (1994).

10. H. C. Lin and S. K. Wu, Acta Metall. 42, 1623 (1994).

11. S. Miyazaki, K. Otsuka, and Y. Suzuki, Scripta Metall. 15, 287 (1981).

12. K. Otsuka and K. Shimizu, Int. Met. Rev. 31, 93 (1986).

13. K. Enami, K. Yamauchi, T. Sato, and K. Takahata, Trans. Mater. Res. Soc. Jpn. 18B, 1021 (1994).

14. K. N. Melton and O. Mercier, Acta Metall. 29, 393 (1981).

15. Y. Kudoh, M. Tokonami, S. Miyazaki, and K. Otsuka, Acta Metall. 33, 2049 (1985).

16. C. S. Zhang, Ph.D. Thesis, Harbin Institute of Technology, (1991).

17. Y. D. Kim and C. M. Wayman, Scripta Metall. Mater. 24, 245 (1990).

18. K. Otsuka, K. Oda, Y. Ueno, and M. Piao, Scripta Metall. Mater. 29, 1355 (1993). 